\title{
Potential Involvement of Melon Fruit in the Long Distance Dissemination of Cucurbit Potyviruses
}

\author{
Hervé Lecoq, Cécile Desbiez, Catherine Wipf-Scheibel, and Myriam Girard, INRA, Station de Pathologie \\ Végétale, B.P. 94, 84143 Montfavet Cedex, France
}

\begin{abstract}
Lecoq, H., Desbiez, C., Wipf-Scheibel, C., and Girard, M. 2003. Potential involvement of melon fruit in the long distance dissemination of cucurbit potyviruses. Plant Dis. 87:955-959.

Papaya ringspot virus (PRSV) and Zucchini yellow mosaic virus (ZYMV) are potyviruses frequently reported in cucurbits in Mediterranean, subtropical, and tropical regions. Occasionally, epidemics are also observed in more temperate regions, but the ways these viruses are introduced into new areas are not yet fully determined. We investigated the possibility that infected imported melon fruit could be a route for the introduction of PRSV and ZYMV. Imported melon fruits of the yellow canary type infected by ZYMV and PRSV were exposed in the fields next to healthy melon or squash bait plants. During this period, aphids were observed landing and probing on the fruits. In four independent experiments using different fruits, 3.1 to $25 \%$ of bait plants were infected by ZYMV and/or PRSV. PRSV was more frequently transmitted to bait plants than ZYMV. Comparison of partial sequences of the isolates from fruits and from bait plants showed a very high, if not complete, identity within each experiment, confirming that a natural transmission did occur from the fruit to the bait plants. These results suggest that globalization of melon production and international trade may be a factor in the spread of cucurbit potyviruses between countries or continents.
\end{abstract}

Potyviruses are among the most important pathogens infecting cucurbit crops worldwide. Presently, three potyvirus species are most commonly reported in surveys of virus infecting cucurbits in different parts of the world: Watermelon mosaic virus (WMV), Papaya ringspot virus (PRSV), and Zucchini yellow mosaic virus (ZYMV) (4,11,14,17,20,22,25). WMV occurs mainly under temperate and Mediterranean climatic conditions while PRSV and/or ZYMV are most often reported in Mediterranean, subtropical, and tropical regions $(5,15,16,19)$. The availability of alternative hosts is partially responsible for this differential geographic distribution. WMV overwinters in many common weeds found in temperate regions, while PRSV and ZYMV have more restricted host ranges and overwinter mainly in winter cucurbit crops or in wild cucurbit species not found in temperate regions $(5,14,19)$. However, occasionally and often locally, severe ZYMV or PRSV epidemics are also reported in temperate growing

Corresponding author: H. Lecoq

E-mail: Herve.Lecoq@avignon.inr.fr

GenBank Accession Numbers for nucleotide sequences are AY016548-AY016551 for ZYMV, and AF548904-AF548908 and AY173115 for PRSV.

Accepted for publication 20 March 2003.

Publication no. D-2003-0522-01R

(C) 2003 The American Phytopathological Society regions where these viruses are usually not detected every year. For instance, in the Avignon area (southeastern France), WMV epidemics were observed every year during the 1981-2002 period, while ZYMV was observed only 11 of 22 years and PRSV only twice (14; H. Lecoq, unpublished). A similar variation in virus occurrence from year to year has also been observed in California, Italy, or Spain $(11,17,22)$.

Two main hypotheses have been raised to explain these occasional and recurrent introductions of PRSV and ZYMV in nonendemic regions: long distance spread by viruliferous aphids or dissemination through the use of infected seeds. Although ZYMV is nonpersistently transmitted by aphids (5), Fereres et al. (8) observed 1\% transmission by Myzus persicae and Aphis gossypii, $30 \mathrm{~h}$ and 10 to $20 \mathrm{~h}$, respectively, after virus acquisition. This retention time could allow long distance spread of ZYMV by aphids carried by the wind from southern regions where the virus is endemic. This has been suggested as the means by which Maize dwarf mosaic virus, another potyvirus, was able to spread from the southern United States to the corn belt region in the north (26). Seed transmission may also contribute to potyvirus introduction into new production areas by creating primary infection sites from which these viruses could be efficiently disseminated by aphids. However, no seed transmission has been reported so far for PRSV (19). ZYMV seed transmission has been observed in Cucurbita spp. in some laboratories (24) but has not been confirmed by others $(10,21)$. Recently, we have not been able to detect any ZYMV seed transmission by observing approximately 70,000 seedlings originating from 12 Cucurbita cultivars infected by four ZYMV isolates (H. Lecoq and C. Wipf-Scheibel, unpublished). However, factors such as virus strain, host genotype, or seed extraction procedures might interfere with seed transmission rates.

A third possible means for long distance virus dissemination is through the international trade of fruit and vegetables for human consumption (3,9). Indeed, the development of long shelf life cultivars, the improvement of packing technologies, and the strong consumer demand for fresh fruits and vegetables all year long has led to a globalization of the cucurbit production. In France, during the off-production season, melon fruits are imported from neighboring countries (Spain and Italy), the Mediterranean Basin (Morocco and Israel), and farther regions (mainly the Caribbean Region-Guadeloupe, Martinique, and the Dominican Republic, or Central America-Costa Rica, Honduras, and Panama) (1). Melons imported in France in 1998 represented 92,385 tons (ca. $10^{8}$ individual fruits) (1), a proportion of which were produced in regions where PRSV and ZYMV are prevalent. In laboratory experiments, aphids can acquire PRSV or ZYMV from infected watermelon and zucchini fruits, respectively $(14,23)$. Similarly, another potyvirus, Plum pox virus, was acquired by aphids from infected apricot and peach fruits (13). In this paper, we investigate the possibility that imported melon fruit could also be a source of virus under natural conditions.

\section{MATERIALS AND METHODS}

Potyvirus detection in commercial imported melon fruits. In the spring, melon fruits of the yellow canary type imported from Central American countries are commonly found in French supermarkets. From April to May 2000, light to severe yellow mosaic symptoms were observed on fruits imported from Costa Rica for sale at Avignon major supermarkets or local open air markets. A sample of 10 fruits from five shops from the Avignon area bearing three brand names, were collected and tested for the presence of potyvirus infection.

Serological tests and virus transmission. The presence of potyviruses in com- 
mercial melon fruits or in test plants was tested by double antibody sandwich enzyme linked immunosorbent assay (DASELISA) with PRSV, WMV, and ZYMV specific polyclonal antisera produced in our laboratory using plants infected by PRSV-E2, WMV-FR, and ZYMV-E15 strains as positive controls $(4,6)$. Immunoglobulin Gs (IgGs) and alkaline phosphatase conjugated IgGs were used at 0.5 $\mu \mathrm{g} / \mathrm{ml}$ and 1/4,000 dilution, respectively. Fruit or leaf samples were ground in the inoculation buffer $\left(0.03 \mathrm{M} \mathrm{Na}_{2} \mathrm{HPO}_{4}\right.$ containing $0.2 \% \mathrm{Na}$-diethyldithiocarbamate) at a ratio of 1:5 (wt/vol). One hundred and fifty microliters of extracts were deposited per well of a microtitration plate, using two wells for each sample. Paranitrophenol (1 $\mathrm{mg} / \mathrm{ml}$ ) was used as a substrate and absorbance $\left(A_{405}\right)$ was measured after 1 to $2 \mathrm{~h}$ using a Titertek Multiskan RC spectrophotometer (Labsystems, Helsinki, Finland). ZYMV isolates were further characterized using a set of 14 monoclonal antibodies (MAbs) produced in our laboratory, as previously described $(5,6)$.

For mechanical inoculations, pieces of melon fruits (skin and flesh) or leaves were triturated in the inoculation buffer (1:5 $\mathrm{wt} / \mathrm{vol}$ ) with a mortar and pestle. Extracted juice was mixed with 400-mesh Carborundum $(75 \mathrm{mg} / \mathrm{ml})$ and activated charcoal $(75$ $\mathrm{mg} / \mathrm{ml}$ ) before being rub inoculated on zucchini squash (Cucurbita pepo, cv. Diamant) or melon (Cucumis melo, cv. Védrantais) cotyledons of 2-week-old plantlets. Aphid transmission of the virus was done using Myzus persicae reared on pepper plants. Aviruliferous aphids were starved for 1 to $2 \mathrm{~h}$ before being allowed a 1 to 2 min acquisition access period on infected fruits or leaves. Aphids were then deposited by groups of three on each of 10 test plants (C. melo cv. Védrantais) for a 2 $\mathrm{h}$ inoculation access period. Melon test plants were then sprayed with an aphicide before being transferred to an insect-proof

Table 1. Papaya ringspot virus (PRSV) or Zucchini yellow mosaic virus (ZYMV) transmission by aphids from infected yellow canary melon fruits in laboratory experiments or in natural conditions

\begin{tabular}{|c|c|c|c|c|c|c|}
\hline \multirow[b]{3}{*}{ Fruit number } & & & \multicolumn{4}{|c|}{ Natural transmission in field conditions ${ }^{\mathrm{a}}$} \\
\hline & \multicolumn{2}{|c|}{$\begin{array}{l}\text { Laboratory transmission } \\
\text { with Myzus persicae }^{\mathrm{b}}\end{array}$} & \multicolumn{2}{|c|}{$\begin{array}{c}\text { Bait plants close to } \\
\text { fruit sources }\end{array}$} & \multicolumn{2}{|c|}{$\begin{array}{c}\text { Bait plants } 50 \mathrm{~m} \text { away } \\
\text { from fruit sources }\end{array}$} \\
\hline & ZYMV & PRSV & ZYMV & PRSV & ZYMV & PRSV \\
\hline F4 & $1 / 10$ & $0 / 10$ & $0 / 8$ & $0 / 8$ & $0 / 8$ & $2 / 8$ \\
\hline F6 & $0 / 10$ & $2 / 10$ & $2 / 8$ & $3 / 8$ & $0 / 8$ & $0 / 8$ \\
\hline F7 & $0 / 10$ & $1 / 10$ & $0 / 16$ & $2 / 16$ & $0 / 16$ & $0 / 16$ \\
\hline F9 & $1 / 10$ & $1 / 10$ & $0 / 16$ & $1 / 16$ & $0 / 16$ & $0 / 16$ \\
\hline
\end{tabular}

a Infected fruits were exposed in the field for a 24-h period. Eight bait plant pots (each containing one 3-week-old melon plant for F4 and F6 or two 2-week-old squash plants for F7 and F9) were located at 1 to $1.4 \mathrm{~m}$ from the melon fruit, and eight bait pots were located $50 \mathrm{~m}$ away from the melon fruit. Following the 24-h exposure period, bait plants were treated with a systemic insecticide and observed for virus symptom development for 4 weeks in an insect-proof greenhouse. Results are expressed as number of bait plants infected by each virus divided by the number of exposed bait plants. No infection by PRSV or ZYMV was observed when melon or squash bait plants were exposed for a 24-h period in the absence of melon fruit.

b Aviruliferous aphids were allowed a 1 to 2 min acquisition access period on infected fruits and transferred by groups of three onto each of 10 melon plants. Results are expressed as number of plants infected by each virus divided by the number of inoculated plants. ter and heated for $5 \mathrm{~min}$ at $65^{\circ} \mathrm{C}$ prior to reverse transcription (RT). RT and polymerase chain reaction (PCR) were performed according to our standard procedure for ZYMV (6). For PRSV, a similar protocol was followed with primers PRSV5': 5'-GCRATGATAGARTCRTGGGG-3' and PRSV-3': 5'-GGRTTATACTGRAGAAGRTG-3' $(\mathrm{R}=\mathrm{A}, \mathrm{G})$ with an annealing temperature of $55^{\circ} \mathrm{C}$. This led to the production of 462- and 587-bp fragments for ZYMV and PRSV, respectively, encompassing the C-terminal part of the polymerase $(\mathrm{NIb})$ coding region and the $\mathrm{N}$ terminal part of the coat protein $(\mathrm{CP})$ coding region. Fragments obtained after PCR amplification were sent for direct sequencing to Genome Express (Grenoble, France). Multiple nucleotide and protein sequence alignments and distance matrix were obtained for ZYMV and PRSV as described (6). Since most sequences available in the databases for PRSV did not include the C-terminal part of the NIb, comparisons and analyses were based only on $\mathrm{CP}$ sequences for this virus. Distance trees were built by the neighbor-joining method with the Neighbor algorithm of the Phylip package (7), and a bootstrap analysis with 1,000 bootstrap samples was performed.

\section{RESULTS}

Serological tests. Ten melon fruits originating from Costa Rica were analyzed using DAS-ELISA for the presence of WMV, PRSV, and ZYMV. All were infected by PRSV and four were also positive for ZYMV. None were infected by WMV. The four fruits coinfected by PRSV and ZYMV (fruits F4, F6, F7, and F9) were selected for further experiments. PRSV and ZYMV isolates could be easily recovered from fruits by mechanical inoculation to melon and zucchini squash test plants (data not shown). ZYMV-F4, -F6, and -F7 reacted similarly to the ZYMV type strain using a set of 14 MAbs. This reaction profile corresponds to the most common ZYMV serotype (5). Isolate ZYMV-F9 did not react with MAbs AB6 and DD2, and only weakly with MAbs DE6 and ED3, corresponding to a serotype not yet reported $(5,6)$.

Aphid transmissions were observed from infected melon fruits to melon test plants in laboratory conditions (Table 1). However, the observed transmission rates were lower (5 and 10\% for ZYMV and PRSV, respectively) than those observed when transmissions were done using infected leaves as virus sources for aphids (ranging from 80 to $100 \%$ ) (data not shown).

Four hundred seeds from each of the four fruits coinfected by PRSV and ZYMV were sown. None of the 1,095 plantlets obtained developed virus symptoms or were positive in DAS-ELISA for ZYMV or PRSV. 
RT-PCR tests and sequence analysis. RT-PCR tests were conducted on extracts from the fruits. The comparison of the four nucleotide sequences of a 250-bp amplified fragment corresponding to the C-terminal part of the NIb and the N-terminal part of the CP genes of ZYMV showed a high level of sequence identity (varying from 98.4 to $99.6 \%$ ). At the amino acid (aa) level, sequences of ZYMV-F4, -F6, and -F7 were identical, while that of ZYMV-F9 contained two aa changes located in the epitopes corresponding to AB6 and DD2 or DE6 MAbs, respectively (Fig. 1). ZYMV isolates from Costa Rica presented $75 \%$ nucleotide sequence identity with isolates from the divergent ZYMV group B including isolates from Réunion Island and 91 to 98.5\% nucleotide sequence identity with isolates from other origins (group A).

Comparison of a 250-bp NIb-CP fragment with that of $30 \mathrm{ZYMV}$ isolates from different origins revealed that Costa Rican isolates clustered together within the ZYMV cluster 1 (6; Fig. 2).

Partial sequences of the PRSV isolates were also established. Isolates PRSV-F4 and PRSV-F6 shared highly similar sequences, while PRSV-F7 was more divergent. Isolate PRSV-F9 presented a sequence closely related to PRSV-F4 and PRSV-F6, but with a few sequence ambiguities suggesting the presence of a PRSVF7-like isolate in mixed infection. Amplification of extracts from F9 fruit with primers specific to isolate PRSV-F7 (PRSV-F75': GTTATGATGAACTAACGCATC and PRSV-F7-3': AAGTTCCATTGGTCCCAAC) led to a sequence of the PRSV-F7 type, named PRSV-F9*, and confirmed the presence of a PRSV-F7-like minor component in the PRSV population infecting the F9 fruit (Fig. 3).

Comparison of the 222-bp N-terminal fragment of the $\mathrm{CP}$ with that of PRSV isolates from diverse origins revealed that Costa Rican isolates clustered together and were more closely related to American isolates than to isolates from Asia (Fig. 4).

Potyvirus infection in bait plants. Soon after exposing a fruit in the fields, alate aphids were observed landing and probing on the fruit skin. Although no taxonomic determination was conducted, the high variability in color, shape, and size of the aphids observed on the fruits suggested that a diversity of species was attracted by the yellow color of the fruit. After various times (generally less than 5 min), aphids were observed to take off from the fruits. In the four independent experiments, 3.1 to $25 \%$ of total bait plants (close and at a $50 \mathrm{~m}$ distance from the source) were infected by PRSV and/or ZYMV (Table 1). Bait plants were found singly infected, except one plant in experiment with F6 fruit, which was infected by PRSV and ZYMV. PRSV was more frequently transmitted to bait plants $(8.3 \%)$ than ZYMV (2.1\%). Most of the infected bait plants were from groups located close to the melon fruit source. However, in one experiment with F4 fruit, two bait plants located $50 \mathrm{~m}$ away from the source fruit were infected by PRSV (Table 1).

No infection by PRSV and ZYMV was observed in the bait plants of the two control experiments where melon or squash bait plants were exposed without exposing an infected melon fruit.

Comparison of ZYMV and PRSV isolates in melon fruit and bait plants. No ZYMV or PRSV epidemics were observed in the Avignon area during the 2000 growing season, and no ZYMV or PRSV natural reservoir have been yet identified in France (H. Lecoq, unpublished). Therefore, it is likely that the viruses found in- fecting the bait plants were originating from the infected melon fruits. However, to rule out the possibility that PRSV and ZYMV were originating from other unknown virus sources, the isolates from bait plants were compared to those present in the corresponding source fruits. For ZYMV, one isolate from a bait plant had exactly the same nucleotide sequence as the isolate from F6 fruit source, while the other isolate differed by only one silent point mutation ( $\mathrm{C}$ to $\mathrm{T}$ change for nucleotide 162 in the $\mathrm{CP}$ ) (Fig. 1). For PRSV and F4, F6, and F7 fruits, all isolates from bait plants had the same amino acid sequence as the isolates from the corresponding source fruit (Fig. 3); one isolate obtained after transmission from F4 fruit differed by one nucleotide without any amino acid change $(\mathrm{C}$ to $\mathrm{T}$ change in the NIb, 25-nt upstream from the beginning of the $\mathrm{CP}$ ). For the F9 fruit that initially contained a mixed PRSV population with strains similar to PRSVF4 and PRSV-F7 (PRSV-F9 and PRSVF9*, respectively), the only isolate obtained after aphid transmission had the

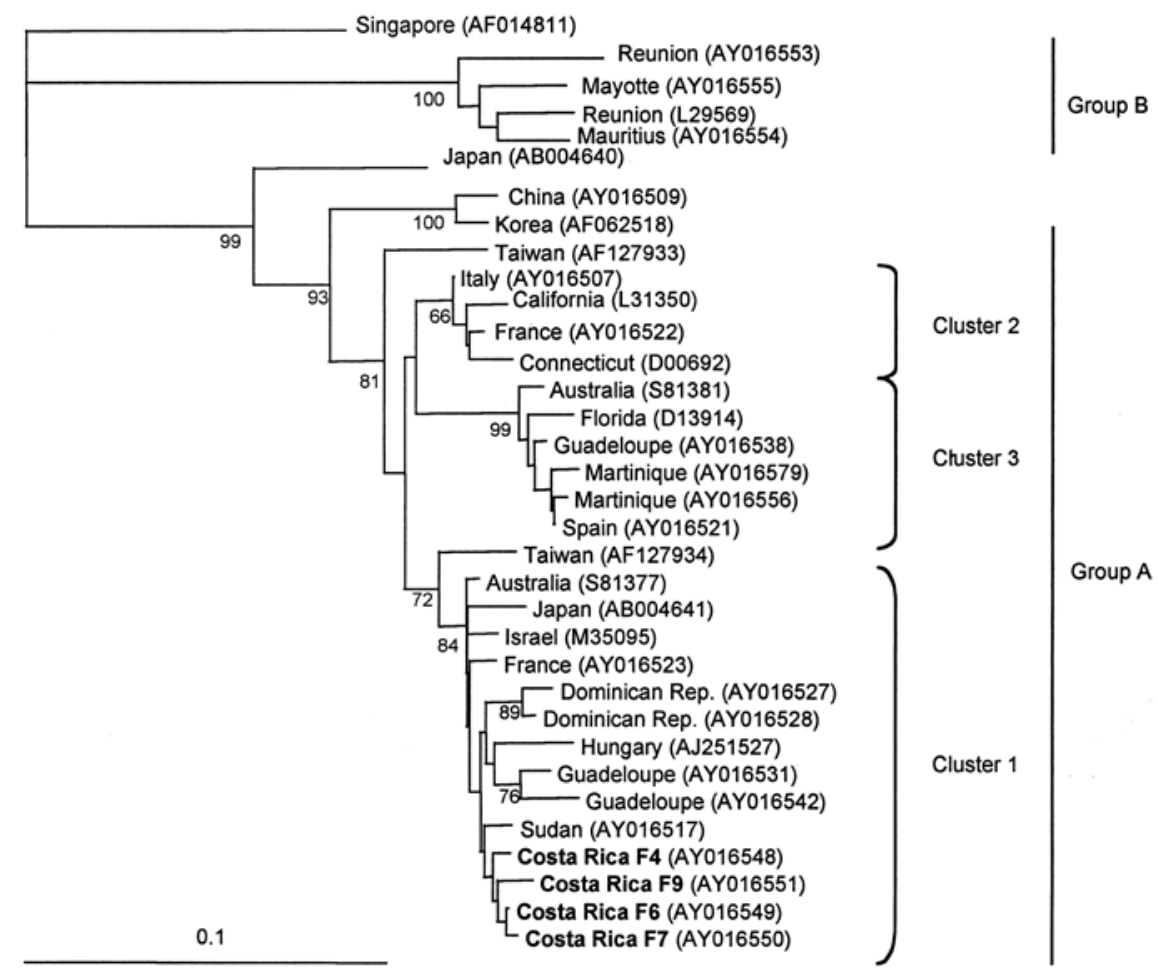

Fig. 2. Distance tree obtained for the nucleotide sequence of the C-terminal part of the polymerase and $\mathrm{N}$-terminal part of the coat protein $(250 \mathrm{nt})$ of 34 Zucchini yellow mosaic virus isolates, including the four isolates from melon fruits from Costa Rica. GenBank Accession Nos. of the isolates are indicated on the tree. Bootstrap values (1,000 bootstraps) above 600 are indicated as a percentage for each node. Scale bar represents a genetic distance of 0.1 .

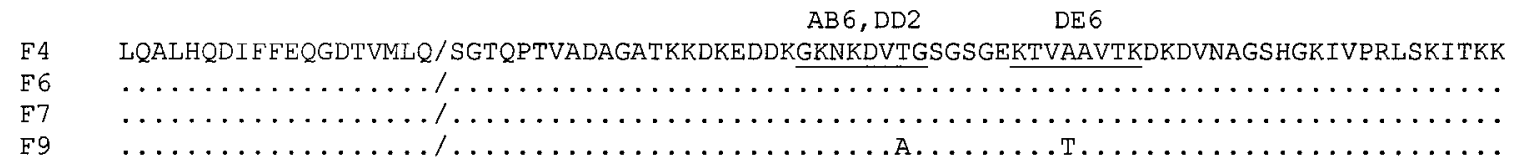

Fig. 1. Amino acid sequence alignments of Zucchini yellow mosaic virus strains F4, F6, F7, and F9 isolated from melon fruits from Costa Rica. The / represents the N-terminal limit of the coat protein. Sequences recognized by monoclonal antibodies AB6 and DD2 or DE6 are underlined. 
same nucleotide sequence as PRSV-F9* (Fig. 3).

\section{DISCUSSION}

Imported fruits and vegetables have long been considered as a means to disseminate viruses between countries and continents $(3,9)$, but experimental data is still lacking to sustain this hypothesis. A prerequisite is that the virus remains infectious in the fruits and that the fruits are sufficiently fresh and attractive so that the vectors can acquire the virus from them. PRSV and ZYMV were isolated from long shelf life melon fruits imported from Costa Rica to France in the spring of 2000. Detection of infectious potyviruses in commercial cucumber, melon, squash, and watermelon fruits has already been reported $(14,23)$, and the incidence of PRSV and ZYMV was described to be high in melon crops in Costa Rica (20). The ZYMV isolates from fruits belonged to the most common cluster of ZYMV strains including isolates from the Caribbean and the United States but also from Europe, Africa, Asia, or Australia (6; Fig. 2). The PRSV isolates from fruits clustered together and were apparently more closely related to American isolates than to isolates from Asia (Fig. 4). This confirms that PRSV populations are present in geographical groups (2), in contrast to ZYMV (6).

Our field experiments indicate that infected melon fruit were efficient virus sources in natural conditions. Indeed, the observation of alate aphids probing on exposed infected fruits and the close serological and molecular relationship between ZYMV and PRSV isolates found in melon fruits and in the corresponding bait plants strongly support that natural transmission did occur from infected melon fruits to melon or squash plantlets. The possible involvement of imported watermelon fruits from southeastern European countries (Bulgaria and Romania) or from Cuba was raised by Schmelzer (23) as a possible source of PRSV in the former German Democratic Republic. This researcher also demonstrated that $M$. persicae could acquire the virus under laboratory conditions by probing on infected fruits. A similar origin was also suggested to explain a severe PRSV epidemic in southern Germany in 1975 (12).

Open-air fruit and vegetable markets are places where aphids could have a chance to visit infected imported melon fruits; in addition, these open-air markets often in- clude nursery shops selling cucurbit seedlings for gardens. So, it is not unrealistic to imagine that infection of one of these cucurbit seedlings could occur from a nearby infected fruit and once transplanted, this seedling might become a primary infection focus from which an epidemic could start. Other places where imported fruits could be exposed to aphids are garbage dumps were unmarketable fruits might be disposed. However, it will be difficult to definitively correlate the occurrence of a PRSV or a ZYMV epidemic with fruit imports since there will always be a time lag between the introduction of the putative virus source and the observation of the epidemics in the field. For that purpose, virus sequence databases could be a very useful way to establish phylogenetic relationships between isolates occurring during epidemics and those described either in exporting countries or isolated from imported fruits.

Seeds carried by infected fruits could also be a potential means of virus introduc- tion. However, none of the 1,095 seedlings obtained from seeds collected from ZYMV- and PRSV-infected fruits were infected, confirming the low, if any, incidence of ZYMV seed transmission in melon (5).

The long shelf life and the bright yellow color of the fruits that we used in these experiments may have favored the PRSV and ZYMV transmission to bait plants. Indeed, yellow is known to be very attractive to alate aphids, in such a way that this color has long been used to make aphid traps (18). It is possible that light yellow, white, or green skinned melon fruits would have been less attractive to aphids than the yellow canary type. In addition, the long shelf life characteristics of this cultivar prevent rapid fruit decay that would also probably make the fruits less attractive to aphids.

ZYMV is one of the best examples of an "emerging" plant virus. First isolated in Italy in 1973 (5), it was associated with very severe virus epidemics in southern

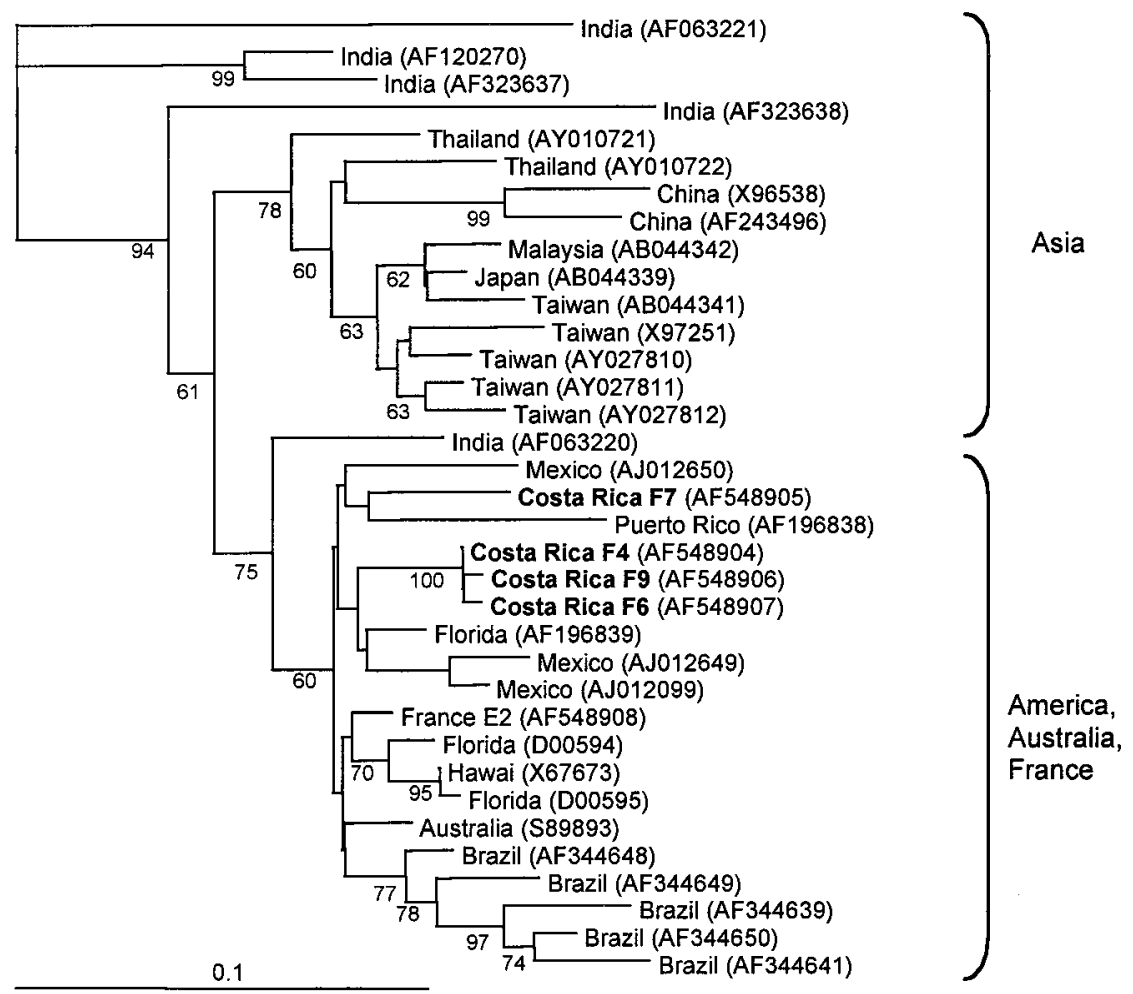

Fig. 4. Distance tree obtained for the nucleotide sequence of the N-terminal region of the coat protein (222 nt) of 35 Papaya ringspot virus isolates, including the four isolates from melon fruits from Costa Rica. GenBank Accession Nos. of the isolates are indicated on the tree. Bootstrap values ( 1,000 bootstraps) above 600 are indicated as a percentage for each node. Scale bar represents a genetic distance of 0.1 .

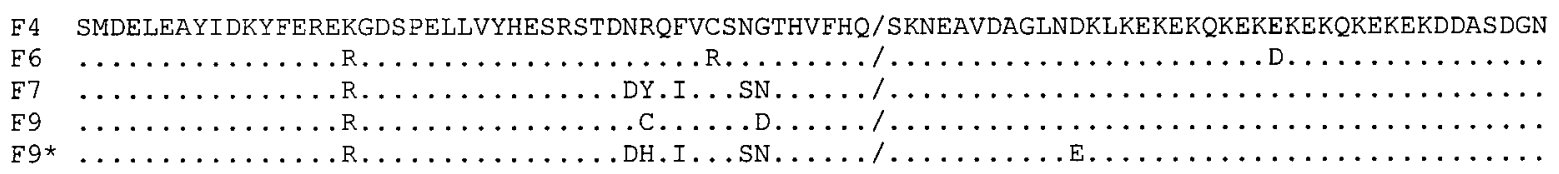

Fig. 3. Amino acid sequence alignments of Papaya ringspot virus strains F4, F6, F7, F9, and F9* isolated from melon fruits from Costa Rica. The / represents the N-terminal limit of the coat protein. Sequence F9 was obtained from the F9 fruit with the PRSV primers (PRSV-5' and PRSV-3'), while sequence F9* was obtained from the same fruit using primers specific for PRSV-F7 isolate (PRSV-F7-5' and PRSV-F7-3'). 
France in 1979 (5). Within a few years, ZYMV was reported worldwide (5). The way ZYMV was disseminated so efficiently within such a short period of time remains a very intriguing epidemiological question to be elucidated. International cucurbit fruit trade might have been one of the factors that have contributed to the rapid ZYMV spread all over the planet.

\section{LITERATURE CITED}

1. Anonymous, 1999. Bilan 1998 fruits et légumes. Interfel, Paris.

2. Bateson, M. F., Lines, R. E., Rewill, P., Chaleeprom, W., Ha, C. V., Gibbs, A. J., and Dale, J. L. 2002. On the evolution and molecular epidemiology of the potyvirus Papaya ringspot virus. J. Gen. Virol. 83:2575-2585.

3. Bos, L. 1983. Introduction to Plant Virology. Pudoc Scientific Publishers, Wageningen, Netherlands.

4. Dahal, G., Lecoq, H., and Albrechtsen, S. E. 1997. Occurrence of papaya ringspot potyvirus and cucurbit viruses in Nepal. Ann. Appl. Biol. 130:491-502.

5. Desbiez, C., and Lecoq, H. 1997. Zucchini yellow mosaic virus. Plant Pathol. 46:809829.

6. Desbiez, C., Wipf-Scheibel, C., and Lecoq, H. 2002. Biological and serological variability, evolution and molecular epidemiology of Zucchini yellow mosaic virus (ZYMV, Potyvirus) with special reference to the Caribbean Islands. Virus Res. 85:5-16.

7. Felsenstein, J. 1989. PHYLIP-Phylogeny Inference Package (version 3.2). Cladistics 5:164-166.

8. Fereres, A., Blua, M. J., and Perring, T. M. 1992. Retention and transmission characteris- tics of zucchini yellow mosaic virus by Aphis gossypii and Myzus persicae (Homoptera: Aphididae). J. Econ. Entomol. 85:759-765.

9. Foster, J. A., and Hadidi, A. 1998. Exclusion of plant viruses. Pages 208-229 in: Plant Virus Disease Control. A. Hadidi, R. K. Khetarpal and H. Koganezawa eds. The American Phytopathological Society, St Paul, MN.

10. Gleason, M. L., and Provvidenti, R. 1990. Absence of transmission of zucchini yellow mosaic virus from seeds of pumpkin. Plant Dis. 74:828.

11. Grafton-Cardwell, E. E., Perring, T. M., Smith R. F., Valencia J., and Ferrar C. A. 1996. Occurrence of mosaic viruses in melons in the Central Valley of California. Plant Dis. 80:1092-1097.

12. Hein, A. 1977. Uber ein Auftreten des Wassermelonenmosaik-Virus 1 an Zucchini (Cucurbita pepo L. var. giromontiina Alef.) in Süddeutschland. Phytopathol. Z. 89:221228.

13. Labonne, G., and Quiot, J. B. 2001. Aphids can acquire Plum pox virus from infected fruits. Acta Hortic. 550:79-83.

14. Lecoq, H, 1992. Les virus des cultures de melon et de courgette de plein champ (II). PHM-Rev. Hortic. 324:15-25.

15. Lecoq, H., Wisler, G., and Pitrat, M. 1998. Cucurbit viruses: the classics and the 'emerging'. Pages 126-142 in: Cucurbitaceae '98 Evaluation and enhancement of Cucurbits germplasm. J. D. McCreight, ed. ASHS Press, Alexandria, VA.

16. Lovisolo, O. 1980. Virus and viroid diseases of cucurbits. Acta Hortic. 88:33-82.

17. Luis Arteaga, M., Alvarez, J. M., AlonsoPrados, J. L., Bernal, J. J., Garcia-Arenal, F., Lavina, A., Batlle, A., and Moriones, E. 1998. Occurrence, distribution, and relative incidence of mosaic viruses infecting field-grown melon in Spain. Plant Dis. 82:979-982.

18. Moericke, V. 1969. Host plant specific colour behaviour by Hyalopterus pruni. Entomol. Exp. Appl. 12:524-534.

19. Purcifull, D. E., Edwardson, J. R., Hiebert, E., and Gonsalves, D. 1984. Papaya ringspot virus. No. 292 in: Descriptions of Plant Viruses. CMI/AAB, Surrey, England.

20. Rivera, C., Villalobos, W., Sánchez, M. V., Zumbado, C., and Rodríguez, C. M. 1993. Identification and distribution of meloninfecting viruses and their vectors in two provinces of Costa Rica. Turrialba 43:210 215.

21. Robinson, R. W., Provvidenti, R., and Shail, J. W. 1993. Tests for seedborne transmission of Zucchini yellow mosaic virus. HortScience 28:694-696.

22. Rubies-Antonell, C., Ballante, M. and Turina M. 1996. Virus infections in melon crops in Central-Northern Italy. Inform. Fitopatologia 7-8:6-10

23. Schmelzer, K. 1965. Nachweiss des Wassermelonenmosaik-Virus von importierten Wassermelonenfrüchten und deren mögliche Bedeutung als Virusquellen. Zentbl. Bakteriol. Parasitenkd. Abt II 119:130-132.

24. Schrijnwerkers, C. C. F. M., Huijberts, N., and Bos L. 1991. Zucchini yellow mosaic virus; two outbreaks in the Netherlands and seed transmissibility. Neth. J. Pl. Pathol. 97:187-191.

25. Ullman, D. E., Cho, J., and German L. 1991. Occurrence and distribution of cucurbit viruses in the Hawaiian Islands. Plant Dis. 75:367-370.

26. Zeyen, R. J., Stromberg E. L., and Kuehnast E. L. 1987. Long-range aphid transport hypothesis for maize dwarf mosaic virus: history and distribution in Minnesota, USA. Ann. Appl. Biol. 111:325-336. 